\title{
Acute Respiratory Distress Syndrome in Pregnancy and Peripartum: Facts and Figures
}

\author{
Nissar Shaikh, Abdulgafoor M. Tharayil, Arshad H. Chanda, Adel E. Ahmed Ganaw, Muhammad Shakeeel Riaz, Stefan Alfred Hubertus Rohrig, Marcus Lance \\ Department of Anesthesia/ICU and Perioperative Medicine, SICU, Hamad Medical Corporation, Doha, Qatar
}

\section{Abstract}

Acute respiratory distress syndrome (ARDS) is a serious condition occurring rarely during pregnancy and peripartum period. ARDS occurs either due to pregnancy associated risk factors or due to the increased risk during pregnancy. Clinical presentation, arterial blood gas, chest X-ray, and computerized tomography will help in the diagnosis of ARDS. Management of ARDS in pregnancy and peripartum period can be summarized by the "ARDS12," including lung protective ventilation (lower tidal volume, higher respiratory rate, positive end expiratory pressure titration), negative fluid balance, neuromuscular blocking agents, prone position, use of inhaled nitric oxide, high frequency oscillation ventilation, extracorporeal membrane oxygenation, extracorporeal carbon dioxide removal, use of corticosteroids and continuing the supportive care. Overall morality from ARDS is showing decreasing trends, and the mortality during pregnancy and peripartum period is significantly lower than in general population.

Keywords: Acute respiratory distress syndrome, arterial blood gas, chest X-ray, excluding cardiogenic pulmonary edema, extracorporeal membrane oxygenation, neuromuscular blocking agents, peripartum, pregnancy, steroids

\section{INTRODUCTION}

Acute respiratory distress syndrome (ARDS) is one of the critical illnesses of pregnancy and peripartum period. It is noncardiogenic pulmonary edema caused by the capillary leak and resulting in increased total lung water. Around $2 \%$ of patients require intensive care unit (ICU) admission during pregnancy or in the peripartum period (100-200 ICU admissions in 10,000 deliveries). Majority of the patients present with bleeding and hypertensive disorders of pregnancy. ${ }^{[1]}$ Mostly, these admissions are in the postpartum period. Fortunately, only $0.1 \%-0.2 \%$ of pregnant patients may have acute respiratory failure or ARDS necessitating invasive mechanical ventilation. ${ }^{[1]}$ These patients are at risk from many conditions specific to pregnancy or other preexisting diseases which can complicate into acute respiratory failure. Maternal hypoxemia and hypercapnia will pose significant risk for both mother and the fetus. ${ }^{[2]}$ In the major ARDS trials, pregnancy is a prominent exclusion criterion, hence the management of pregnant patients with ARDS depends mainly on clinical experience or from the case reports. In this review, we will

\begin{tabular}{|l|l|}
\hline \multicolumn{2}{|c|}{ Access this article online } \\
\hline Quick Response Code: & Website: \\
\hline & www.ijrconline.org \\
\hline
\end{tabular}

discuss ARDS in pregnancy and peripartum period in the following headings.

1. Physiological changes in pregnancy

2. Etiology of acute respiratory failure and ARDS in pregnancy and peripartum period

3. Definition and Diagnosis of ARDS in pregnancy

4. Management of ARDS in pregnancy

5. Outcome of ARDS in pregnancy.

\section{Physiological Changes in Pregnancy}

Pregnancy is associated with many physiological adaptations in the mother to meet increased demands by the mother and fetus. Table 1 summarizes respiratory changes in pregnancy.

Address for correspondence: Dr. Abdulgafoor M. Tharayil, Hamad Medical Corporation, Doha, Qatar. E-mail: agafoormt@gmail.com

This is an open access journal, and articles are distributed under the terms of the Creative Commons Attribution-NonCommercial-ShareAlike 4.0 License, which allows others to remix, tweak, and build upon the work non-commercially, as long as appropriate credit is given and the new creations are licensed under the identical terms.

For reprints contact: reprints@medknow.com

How to cite this article: Shaikh $\mathrm{N}$, Tharayil AM, Chanda $\mathrm{AH}$, Ahmed Ganaw AE, Riaz MS, Hubertus Rohrig SA, et al. Acute respiratory distress syndrome in pregnancy and peripartum: Facts and figures. Indian J Respir Care 2020;9:12-9.

Received: $16-07-2019$

Accepted: $27-12-2019$

Revised: $21-12-2019$ Published: 08-01-2020 
Anatomical and functional changes in the maternal respiratory system and additional fetal requirements lead to increased $\mathrm{PaO}_{2}(100-110 \mathrm{mmHg}), 20 \%-33 \%$ increased $\mathrm{O}_{2}$ consumption, $30 \%-45 \%$ increase in cardiac output, increased tidal volume and minute ventilation, decreased $\mathrm{PaCO}_{2}(27-34 \mathrm{mmHg})$, chronic respiratory alkalosis ( $\mathrm{pH} 7.4-7.45)$, reduced serum bicarbonate $(18-21 \mathrm{mmol} / \mathrm{L})$, reduced functional residual capacity and decreased chest wall compliance. In summary, pregnant patients have decreased oxygen reserves while the oxygen demands are increased. ${ }^{[3]}$

\section{Foetal Oxygen Delivery and Determinants of Uterine Oxygen Delivery}

Maternal delivery of oxygen through the placenta to the fetus occurs through the intervillous space of chorionic plate to the fetal umbilical vein, which results in placental transfer of oxygen [Figure 1]. The fetal hemoglobin contains two gamma subunits instead of beta subunits as in adult hemoglobin. This prevents the binding of 2, 3-DPG, which results in a left-shifted oxyhemoglobin dissociation curve, favoring oxygen loading at a low $\mathrm{PaO}_{2}$. carbon dioxide $\left(\mathrm{CO}_{2}\right)$ is unloaded from the umbilical artery to the uterine vein, as the $\mathrm{PaCO}_{2}$ in fetal.

Umbilical artery is greater than the $\mathrm{PaCO}_{2}$ of maternal uterine vein. ${ }^{[2,3]}$ Double Bohr and double Haldane effects play an important role in the fetomaternal transfer of oxygen and $\mathrm{CO}_{2}$.

There is a 20 -fold rise in uterine artery blood flow during pregnancy, which is the greatest physiological change experienced during the human lifespan. The determinants of uterine oxygen delivery are the maternal $\mathrm{PaO}_{2}$, hemoglobin concentration and saturation, alkalosis causing leftward shift of oxyhemoglobin dissociation curve which increases $\mathrm{O}_{2}$ affinity and decreases $\mathrm{O}_{2}$ transfer, uterine artery blood flow, cardiac output, hypotension and/or increased endogenous or exogenous sympathetic stimulation. ${ }^{[4]}$

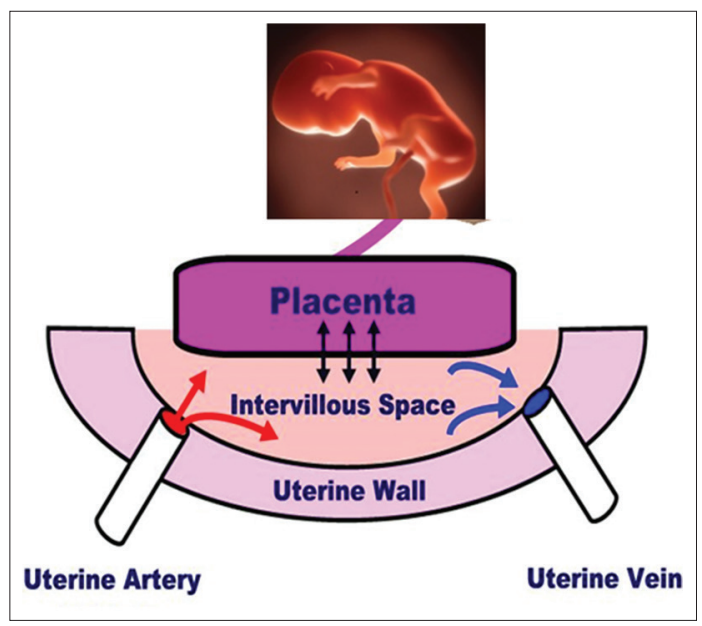

Figure 1: Foetal oxygen delivery

\section{Etiology of Acute Respiratory Failure and Acute Respiratory Distress Syndrome in Pregnancy and Peripartum}

The pregnant patients are predisposed to ARDS by various mechanisms, including increased blood volume, decreased serum albumin level, ${ }^{[5]}$ upregulation of components of acute inflammatory response and increased capillary leak. ${ }^{[6]}$ The etiological factors could be pregnancy associated, increased risk due to pregnancy, not related to pregnancy or nonspecific etiological factors [Table 2].

\section{Pregnancy Associated Factors \\ Chorioamnionitis}

At the onset of labor or with rupture of the ovular membranes, bacteria from the lower genital tract could ascend into the

\begin{tabular}{ll}
\hline \multicolumn{2}{l}{ Table 1: Summary of respiratory changes of pregnancy } \\
\hline Parameters & Changes \\
\hline Residual volume & Decreased by $15 \%$ \\
FRC & Decreased by $20 \%$ \\
Expiratory reserve volume & Decreased by $25 \%$ \\
Inspiratory reserve volume & Increased by $5 \%$ \\
Inspiratory capacity & Increased by $15 \%$ \\
Tidal volume & Increased by $45 \%$ \\
Total lung capacity & Decreased by $5 \%$ \\
Vital capacity & No change \\
Closing capacity & No change \\
FEV1 & No change \\
FEV/FVC & No change \\
Chest becomes barrel-shaped & \\
Upward movement of the diaphragm & \\
\hline FVC: Forced vital capacity, FEV1: Forced expiratory volume in $1 \mathrm{~s}$, \\
FRC: Functional residual capacity
\end{tabular}

Table 2: Aetiology of acute respiratory failure and acute respiratory distress syndrome in pregnancy and peripartum period

\begin{tabular}{|c|c|}
\hline Aetiology & Types \\
\hline \multirow{6}{*}{$\begin{array}{l}\text { Pregnancy } \\
\text { related }\end{array}$} & ARDS due to chorioamnionitis \\
\hline & ARDS related to placental abruption \\
\hline & Amniotic fluid embolism \\
\hline & Tocolytic-associated pulmonary edema \\
\hline & Peripartum cardiomyopathy induced pulmonary edema \\
\hline & Pulmonary edema due to preeclampsia \\
\hline \multirow{5}{*}{$\begin{array}{l}\text { Increased } \\
\text { risk in } \\
\text { pregnancy }\end{array}$} & Venous thromboembolism and pulmonary embolism \\
\hline & Gastric acid aspiration \\
\hline & Asthma \\
\hline & ARDS due to sepsis \\
\hline & Viral Pneumonia \\
\hline \multirow{4}{*}{$\begin{array}{l}\text { Other } \\
\text { conditions }\end{array}$} & Pancreatitis \\
\hline & Drugs/toxins \\
\hline & Acute chest syndrome in sickle cell disease \\
\hline & Trauma \\
\hline
\end{tabular}

ARDS: Acute respiratory distress syndrome 
Shaikh, et al.: ARDS in pregnancy and peripartum

amniotic cavity. This ascending route is the most common pathway for development of intra-amniotic infection. Although it is the common cause for sepsis in peripartum period, it rarely complicates into ARDS. ${ }^{[7]}$

\section{Placental abruption}

Abruptio placentae is the separation of normally implanted placenta after 20 weeks of gestation and before birth of fetus. It is frequently associated with massive blood and blood product transfusion and may lead to ARDS. ${ }^{[8]}$

\section{Amniotic fluid embolism}

Occurs in around 7/100,000 pregnancies, it is commonly associated with labour and delivery or may occur following manipulation of uterus. It is frequently manifested by severe dyspnea and hypoxemia, convulsions, and in extreme cases cardiovascular collapse and cardiac arrest. The amniotic fluid embolism patients rescued from the initial event may develop disseminated intravascular coagulation and ARDS. ${ }^{[9]}$ The risk factors for amniotic fluid embolism are advanced maternal age, multiparity, previous caesarean section, laceration of low uterine segment and meconium stained amniotic fluid.

\section{Increased Risk in Pregnancy}

\section{Transfusion related acute lung injury}

Pregnant patients due to various etiological reasons are at the risk of hemorrhage in antepartum, partum and postpartum period, requiring massive transfusion of blood and blood products and this leads to transfusion related acute lung injury (TRALI). ${ }^{[10]}$ TRALI is pathologically a noncardiogenic pulmonary edema previously known as "transfused ARDS" because of the same pathognomonic features indistinguishable from ARDS, but associated with plasma transfusion.

\section{Pulmonary embolism}

The risk of acute pulmonary embolism (PE) is increased five-to six-times during pregnancy. ${ }^{[11]}$ This appears to be a consequence of several factors, including changes in the clotting factors and an increased likelihood of venous stasis. Predisposing factors include obesity, older age, and a personal or family history of thromboembolic disease, inherited thrombophilia, anti-phospholipid syndrome, trauma, caesarean delivery, and immobility. ${ }^{[12]}$

\section{Asthma and its exacerbation}

Asthma is prevalent among $4 \%-8 \%$ of pregnant patients, ${ }^{[13]}$ and $20 \%-36 \%$ of them have an exacerbation during their pregnancy. ${ }^{[14]}$

\section{Pneumonia}

Community-acquired pneumonia is a common cause of acute respiratory failure in pregnant patients. Most common pathogens are same as those found in nonpregnant patients, mainly streptococcus pneumoniae, hemophilus influenza, mycoplasma pneumoniae, legionella, chlamydia pneumoniae, and influenza A. Reduction in cell-mediated immunity associated with pregnancy (particularly during the third trimester) also predisposes women to higher risk for severe pneumonia and disseminated disease from atypical pathogens, such as herpes virus, varicella, and coccidioidomycosis. ${ }^{[15]}$

\section{Pulmonary aspiration}

Aspiration of gastric contents is common during labor or immediate postpartum period. It may be the effects of sedation, analgesia, increased intra-abdominal pressure. The risk factors include increased intra-abdominal pressure, relaxation of the lower esophageal sphincter, and delayed gastric emptying. ${ }^{[16]}$

\section{Sepsis}

Incidence of sepsis in pregnancy varies between $0.1 \%$ and $0.3 \%$, risk factors being advanced maternal age, obesity, insulin-dependent diabetes mellitus, multiple pregnancies, invasive diagnostic or therapeutic interventions. Dysfunctional intrinsic defense mechanisms in preterm labor can predispose the mother to sepsis. Incidence of peripartum sepsis is 3 times higher in preterm deliveries than in full term deliveries. Intra-amniotic infection is a significant predisposing factor for development of maternal sepsis. Postpartum sepsis is reported to be 3 times more common after the lower segment caesarean section than after the vaginal delivery. ${ }^{[17]}$

\section{Conditions Causing Acute Respiratory Distress Syndrome in Pregnancy}

\section{Acute pancreatitis}

Acute pancreatitis in pregnancy is a common problem, the annual incidence of acute pancreatitis in pregnancy ranges from 1 in 1000 to 1 in 10,000, more frequent in $3^{\text {rd }}$ trimester. The risk factors are advancing gestational age and frequency of gallstones in pregnancy. Principally acute pancreatitis has a good prognosis in pregnancy and peripartum, rarely causing ARDS $^{[18]}$ as per a 5-year observational study by Vishnupriya et al. among pregnant patients in a tertiary hospital in India.

\section{Trauma}

Most common traumatic injuries are assaults, motor vehicle accidents, falls, and partner abuse. Trauma complicates 1 in 12 pregnancies but 9 out of 10 traumatic injuries during pregnancy are fortunately minor injuries. ${ }^{[19]}$

\section{Acute chest syndrome}

Pregnancy can be associated with sickle cell disease and those patients are at risk of developing acute chest syndrome which presents with acute respiratory failure. It can progress to ARDS. ${ }^{[20]}$ Table 2 depicts the various risk factors associated with the development of acute respiratory failure and ARDS in pregnant patients.

\section{Definition and Diagnosis}

The ARDS definition was refined in 2012 [Table 3]. History of primary pathology or increased risk are important factors in developing ARDS in pregnancy and peri-partum period. The respiratory symptoms may be confused with changes of pregnancy. Presence of fever should raise the suspicion 
Shaikh, et al:: ARDS in pregnancy and peripartum

of infection particularly when combined with inflammatory markers such as increased white cell count, $C$ reactive protein or procalcitonin. An arterial blood gas $(\mathrm{ABG})$ and chest $\mathrm{X}$-ray should be performed, which demonstrates hypoxia and diffuse bilateral infiltrates [Figure 2] respectively. Both are the essential components for the diagnosis of ARDS [Table 3]. Computerized tomography (CT) chest if performed, will show more details of lung involvement [Figure 3] though it is not recommended or needed to establish the diagnosis or grading of ARDS. Table 3 shows the comparison between American European Consensus definition and the Berlin definition. Figure 2 shows the typical findings in chest X-ray of ARDS patients and Figure 3 shows the CT chest findings in ARDS patients. Advanced imaging studies should be done only if diagnosis is difficult, considering the risk of radiation to mother and fetus. Table 4 shows the radiation hazard with various imaging techniques. Advanced investigations such as proBNP, cardiac troponin, transthoracic or transoesophageal echocardiogram are helpful in differentiating from cardiogenic pulmonary edema.

\section{Management}

Initially the standard management of respiratory distress irrespective of the cause of the ARDS should be in place. A reasonable goal for pregnant patients would be to maintain the oxygen saturation $>95 \%$ to optimize the fetal oxygen content. Adequate fetal oxygenation requires a maternal arterial oxygen tension $\left(\mathrm{PaO}_{2}\right)>70 \mathrm{mmHg}$. When the ARDS patients require mechanical ventilation, their management may be complicated by difficult intubation during pregnancy and peripartum period because of the upper airway edema, narrowed airway caliber which may necessitate the presence of adequate difficult airway equipment. Another important factor is that the pregnant patients have hypocapnia due to hyperventilation. Hence their arterial $\mathrm{CO}_{2}$ tension $\left(\mathrm{PaCO}_{2}\right)$ tends to be lower than in nonpregnant individuals and ventilator setting should be set up accordingly.

In general, the ARDS management includes 12 parameters [Table 5].

\section{Standardized Mechanical Ventilation}

Generally mechanical ventilation should be optimized to prevent volutrauma, barotrauma, biotrauma, and atelectrauma. Lung protective strategies, should be followed

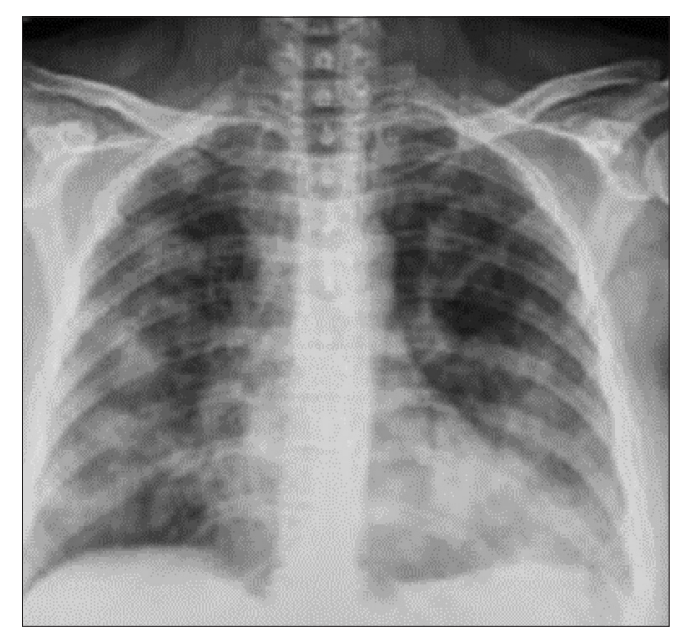

Figure 2: Chest X-ray showing bilateral patchy infiltrates

\begin{tabular}{|c|c|c|}
\hline Characteristic & AECC definition 1994 & Berlin Definition 2012 \\
\hline Timing & Acute, No specific time given & Maximum within a week after a trigger insult \\
\hline Imaging & $\begin{array}{l}\text { Chest X-ray with bilateral } \\
\text { infiltrates }\end{array}$ & $\begin{array}{l}\text { Chest X-ray or CT scan with bilateral infiltrates, not fully explained by } \\
\text { effusion, lung collapse or nodules }\end{array}$ \\
\hline $\begin{array}{l}\text { Noncardiogenic } \\
\text { source of edema }\end{array}$ & $\begin{array}{l}\text { Confirmation of nonelevated } \\
\text { left atrial pressure }\end{array}$ & $\begin{array}{l}\text { Respiratory failure not completely explained by excessive volume } \\
\text { loading or cardiac failure }\end{array}$ \\
\hline \multirow[t]{4}{*}{ Classification } & Based on $\mathrm{PaO}_{2} / \mathrm{FiO}_{2}$ & Based on $\mathrm{PaO}_{2} / \mathrm{FiO}_{2}$ along with $\mathrm{PEEP} \geq 5 \mathrm{~cm} \mathrm{H}_{2} \mathrm{O}$ \\
\hline & Acute lung injury: $\leq 300$ & Mild: $201-300$ \\
\hline & ARDS: $\leq 200$ & Moderate: $101-200$ \\
\hline & - & Severe: $\leq 100$ \\
\hline $\begin{array}{l}\text { Predisposing } \\
\text { condition }\end{array}$ & Not specified & $\begin{array}{l}\text { If none identified, then need to rule out hydrostatic edema with } \\
\text { additional data like Echocardiogram or other hemodynamic parameters }\end{array}$ \\
\hline
\end{tabular}

\section{Table 4: Risk of radiation}

\begin{tabular}{|c|c|c|c|}
\hline Investigation & $\begin{array}{l}\text { Maternal breast } \\
\text { exposure (m Gy) }\end{array}$ & $\begin{array}{l}\text { Foetal radiation } \\
\text { exposure (mGy) }\end{array}$ & Maternal and foetal risk of radiation \\
\hline Chest radiograph & 0.2 & 0.010 & Lesser risk to foetus \\
\hline Ventilation-perfusion scan & $<1.5$ & $0.20-1.0$ & Lesser exposure to maternal breast \\
\hline $\mathrm{CT}$ chest/angiogram & $10-18$ & $0.1-0.8$ & Significant exposure to maternal breast \\
\hline
\end{tabular}

CT: Computerized tomography 
Shaikh, et al.: ARDS in pregnancy and peripartum

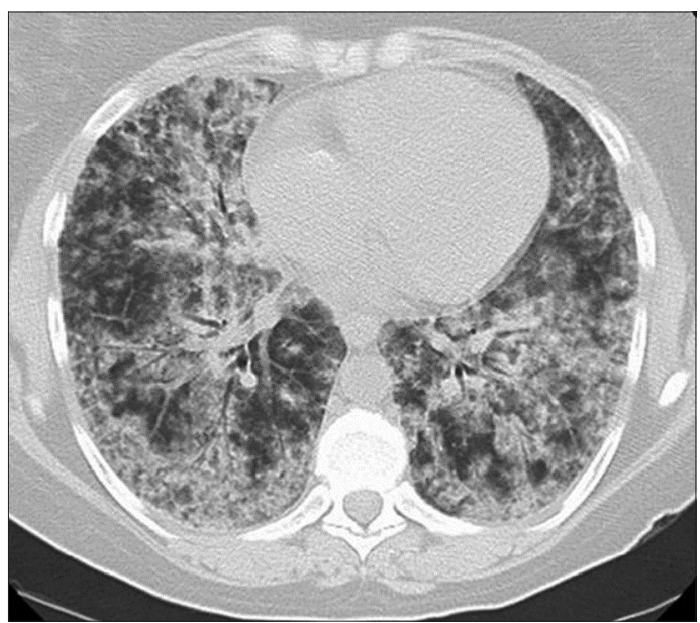

Figure 3: Computerized tomography chest showing bilateral patchy consolidations

\begin{tabular}{l}
\hline Table 5: Acute respiratory distress syndrome 12 \\
\hline Lower tidal volume (lung protective strategy) \\
Higher respiratory rate \\
PEEP titration \\
Negative fluid balance \\
Neuromuscular blocking agents \\
Prone position \\
Inhaled nitric oxide \\
High frequency oscillation \\
ECMO \\
ECCO $\mathrm{R}$ \\
Corticosteroids \\
Supportive care \\
\hline ECMO: Extracorporeal membrane oxygenation, $\mathrm{ECCO}_{2} \mathrm{R}:$ Extracorporeal \\
carbon dioxide removal, PEEP: Positive end expiratory pressure
\end{tabular}

which include lower tidal volume $(6 \mathrm{ml} / \mathrm{kg})$, increasing the respiratory rate to get a reasonable minute ventilation appropriate for the physiological changes in pregnancy as much as possible. Adjust or increase the positive end expiratory pressure (PEEP) and decrease the fraction of inspired oxygen $\left(\mathrm{FiO}_{2}\right)$ by following the PEEP: $\mathrm{FiO}_{2}$ table. Permissive hypercapnia with a $\mathrm{pH}$ of $\geq 7.25$ should be acceptable though the physiology of pregnancy demands mild alkalosis. Plateau pressure should be kept $\leq 30 \mathrm{~cm} \mathrm{H}_{2} \mathrm{O}$. More recently, driving pressure (plateau pressure-PEEP) is considered to be more important than tidal volume and plateau pressure and worth monitoring. The driving pressure in ARDS patients is directly and independently associated with mortality. ${ }^{[2]}$ Despite the advantages of monitoring and controlling driving pressure in ARDS patients, it does not reflect the true transpulmonary driving pressure which is more precisely correlated with ventilator induced lung injury in obese patients and patients with high intraabdominal pressure. ${ }^{[22]}$ Recruitment maneuvers were initially recommended to open the lungs and higher PEEP to keep it open, but a recent meta-analysis showed that it might increase mortality and decrease ventilator free days and higher incidence of barotrauma. ${ }^{[23]}$

Special considerations in pregnant patients include aiming for a higher $\mathrm{SpO}_{2}$ as adequate foetal oxygenation requires a $\mathrm{PaO}_{2}$ of $70 \mathrm{mmHg}$, which corresponds to a maternal $\mathrm{SpO}_{2}$ of about $95 \%,{ }^{[24]}$ a lower $\mathrm{PaCO}_{2}$ target of 30-32 with mild respiratory alkalosis to resemble maternal physiology ${ }^{[25]}$ and a higher PEEP to mitigate the atelectasis induced by gravid uterus. However, a very low $\mathrm{PaCO}_{2}$ can affect the uterine blood flow and should be avoided.

\section{Negative Fluid Balance}

It is commonly said in the critical care practice that "the dry lungs are happy lungs." As the pathological change in ARDS is the fluid accumulation in the interstitial tissues of the lung, by restricting fluid intake and keeping the fluid balance negative, patients will benefit from decreased lung water content. Though the fluid and catheter treatment trial had not shown any beneficial effect on mortality with the conservative fluid therapy, it resulted in more days free from mechanical ventilation and ICU stay. ${ }^{[26]}$

\section{Neuromuscular Blocking Agents}

Neuromuscular blocking agents (NMBA) might improve the mechanical viscoelastic properties of the chest wall. Abolition in spontaneous ventilatory activity increases the total thoracopulmonary compliance because of the improved ventilator patient synchrony and a decrease in the expiratory muscular activity, which will have an oxygen sparing effects as well. However, prolonged use of NMBA particularly in combination with steroid will increase the chances of critical illness neuromuscular abnormality. ACURASYS study showed the beneficial effect of the early use of NMBA in ARDS patients..$^{[27]}$ However a recently published randomised trial called ROSE trial by the National Heart, Lung and Blood Institute PETAL Clinical Trials Network found no meaningful improvement in mortality with neuromuscular blocking agent and light sedation without NMBA. ${ }^{[28]}$ Unfortunately, this study was unblinded with significant patients lost at screening because they received a NMBA before randomization. Moreover, depth of neuromuscular block was not monitored (apparently to mimic ACURASYS trial) but in contrast to ACURASYS trial, light sedation was used in this trial which could have increased oxygen consumption.

\section{Prone Positioning in Pregnancy}

Ventilation in prone position improves oxygenation in all the patients by reopening the posterior dependent consolidated areas of the ARDS lungs. Up to $60 \%$ of patients show improvement in oxygenation after prone ventilation. ${ }^{[29]}$ Prone positioning to improve oxygenation in ARDS patients has been known since late 70's, but its use in clinical practice was not significantly common, till the Proning Severe ARDS Patients trial showed a survival benefit. ${ }^{[30]}$ Proning was once considered risky in pregnant patients for the concern of foetal well-being. Hence, there are few case reports 
Shaikh, et al.: ARDS in pregnancy and peripartum

of prone position successfully used in patients with ARDS. ${ }^{[1,32]}$ Samanta et $a l .{ }^{[33]}$ used prone positioning as a rescue therapy for their pregnant patient who failed to oxygenate adequately with $100 \%$ oxygen. The authors used large rollers underneath chest and iliac crest and used cardiac tocography (CTG) to monitor foetal well-being. Proning is not free from complications, and utmost precautions are essential. Apart from usual care, pregnant patients require extra precautions to avoid any external abdominal pressure. Chest and hips should be significantly elevated than in nonpregnant patients to avoid compression of the abdomen. In addition, the face and particularly the eyes should be protected. Continuous foetal monitoring with CTG is a requirement and needs trained and dedicated supporting staff. Agood team work is the key for success.

\section{INHALED VASODILATORS}

\section{Nitric oxide}

Although inhaled nitric oxide (iNO) improves oxygenation modestly, a recent Cochrane systematic review could not show improvement of morbidity or mortality The Food and Drug Administration has not approved the use of inhalational iNO during pregnancy. Moreover, it is not known whether iNO can cause fetal harm, or whether NO is excreted in human milk. ${ }^{[33]}$ In contrast it increases the risk of renal impairment. ${ }^{[34]}$ So, this therapy cannot be recommended for the general management of ARDS in pregnancy. Not much of the literature is available about other inhaled vasodilators uses in pregnancy and peripartum in ARDS patients.

\section{High frequency oscillation}

High-frequency ventilation is a form of mechanical ventilation that uses the lung protective benefits of very low tidal volumes less than anatomical dead space combined with very high respiratory rates ( $>60$ breaths/min). Although theoretically this sounds good, the strategy could not show improved mortality in ARDS patients. ${ }^{[35]}$

\section{Extracorporeal membrane oxygenation}

Sharma and colleagues reported cases of extra corporeal life support during pregnancy and postpartum period, published between 2009 and 2014. They reported that the overall maternal survival as $80 \%$ and fetal survival as $70 \%{ }^{[36]}$

However, Nair et al. reported that extracorporeal membrane oxygenation (ECMO) in pregnancy was technically challenging, bleeding was common leading to large volumes of blood transfusion which contributed largely to the mortality. ${ }^{[37]}$ Moore et al. presented their results of ECMO during pregnancy and concluded that ECMO is effective and relatively safe for the mother and fetus. In their study the authors found that ECMO during pregnancy had a maternal survival rates of $77.8 \%$ and perinatal survival of $65.1 \%{ }^{[38]}$ which is in line with the results from Sharma et al.

\section{Extracorporeal carbon dioxide removal}

This is a relatively upcoming new technology, which mainly targets the removal of $\mathrm{CO}_{2}$ only. In that sense the application of this technique will be of limited value as the ARDS is mainly a hypoxic disease. However, literature about its application during pregnancy is limited to some case reports only. ${ }^{[39]}$

\section{Corticosteroids}

Steroids in ARDS have been used by clinicians in 3 different situations: prevention of ARDS in high risk patients, early treatment of ARDS with high-dose and short-course therapy, or prolonged therapy in un-resolving ARDS. There is no evidence to support the routine use of corticosteroids for the prevention of ARDS in high risk patients while their use has beneficial effect in un-resolving ARDS cases as per earlier studies. ${ }^{[40]}$ A recent consensus paper by multispecialty task force of 16 international experts in critical care medicine, endocrinology, guideline methods, recommends the use of systemic corticosteroids in moderate to severe ARDS within 14 days of onset. ${ }^{[41]}$ These principles should be applicable to pregnant patients with ARDS as well. However, there is no specific trial in this population.

\section{Supportive care}

It is of vital importance to continue supportive care apart from ARDS management alone. Other supportive care means interventions that sustain life and prevent complications, but do not treat the underlying cause of the critical illness. It includes sedation, pain control, hemodynamic support (vasopressors), monitoring of vital signs, adequate volume management, nutritional support, stress ulcer prophylaxis, and venous thromboembolism prophylaxis.

\section{Outcome}

The overall mortality in nonpregnant patients from severe ARDS is showing a decreasing trend which is directly mainly driven by improved strategies in mechanical ventilation with the limitation of driving pressures in particular. ${ }^{[42]}$

However, mortality of severe ARDS in pregnancy is comparatively lower and reported to be $9 \%$, and the risk factors are prolonged ventilation, renal failure requiring dialysis, liver failure, amniotic fluid embolism, influenza and septic obstetric emboli. ${ }^{[43]}$

\section{SUMmARY}

ARDS is one of the critical illnesses of pregnancy and peripartum period. It is noncardiogenic pulmonary edema caused by the capillary leak and resulting in increased total lung water. ARDS in pregnancy and peripartum period can be caused by the pregnancy related conditions such as amniotic fluid embolism, hypertensive disorders of pregnancy or other conditions such as pneumonia, PE and sepsis.

In combination with the clinical parameters, ABG and imaging studies are needed to confirm the diagnosis of ARDS excluding the cardiogenic pulmonary oedema using advanced hemodynamic monitoring or echocardiography.

In the management of ARDS it is of vital importance to have optimized ventilator strategies with the limitation and control of the plateau pressure and accepting a higher partial pressure 
Shaikh, et al.: ARDS in pregnancy and peripartum

of $\mathrm{CO}_{2}$. To achieve this goal, proning of these patients and extracorporeal oxygenation are accepted methods. In contrast high frequency oscillation is out of practice as it showed limited benefit. Pharmacologically, early course of muscle relaxant might have beneficial effect on oxygenation for selected group of patients while steroid therapy remains controversial and inhalational therapy might even harm.

Finally, supportive care such as ulcer prophylaxis, nutrition, and deep venous thrombosis prophylaxis are important for the basic management.

The overall ARDS mortality in pregnancy and peripartum period is lesser than the general population and prolonged ventilation, amniotic fluid embolism and organ failure increases the risk of death in ARDS patient in pregnancy and peripartum period.

\section{Financial support and sponsorship}

Nil.

\section{Conflicts of interest}

There are no conflicts of interest.

\section{REFERENCES}

1. Pollock W, Rose L, Dennis CL. Pregnant and postpartum admissions to the intensive care unit: A systematic review. Intensive Care Med 2010;36:1465-74.

2. Lapinsky SE. Acute respiratory failure in pregnancy. Obstet Med 2015;8:126-32.

3. Soma-Pillay P, Nelson-Piercy C, Tolppanen H, Mebazaa A. Physiological changes in pregnancy. Cardiovasc J Afr 2016;27:89-94.

4. Carter AM. Placental Gas Exchange and the Oxygen Supply to the Fetus. Compr Physiol 2015;5:1381-403.

5. Bandi VD, Munnur U, Matthay MA. Acute lung injury and acute respiratory distress syndrome in pregnancy. Crit Care Clin 2004;20:577-607.

6. Perry KG Jr., Martin RW, Blake PG, Roberts WE, Martin JN Jr. Maternal mortality associated with adult respiratory distress syndrome. South Med J 1998;91:441-4.

7. Carmona F, Fábregues F, Alvarez R, Vila J, Cararach V. A rare case of chorioamnionitis by Morganella morganii complicated by septicemia and adult respiratory distress syndrome. Eur J Obstet Gynecol Reprod Biol 1992;45:67-70.

8. Singh Y, Shankar A, Rohatgi S. Abruptio placentae leading to fetal death and adult respiratory distress syndrome. Med J Armed Forces India 2008;64:389-90.

9. Abenhaim HA, Azoulay L, Kramer MS, Leduc L. Incidence and risk factors of amniotic fluid embolisms: A population-based study on 3 million births in the United States. Am J Obstet Gynecol 2008;199:49. e1-8.

10. Bharati S, Chakrabarty A, Bhattacharyya P. Transfusion-related acute lung injury in a case of acute ruptured ectopic pregnancy. Saudi J Health Sci 2014;3:43-6.

11. Bennett A, Chunilal S. Diagnosis and management of deep vein thrombosis and pulmonary embolism in pregnancy. Semin Thromb Hemost 2016;42:760-73.

12. Bates SM, Greer IA, Middeldorp S, Veenstra DL, Prabulos AM, Vandvik PO. VTE, thrombophilia, antithrombotic therapy, and pregnancy: Antithrombotic Therapy and Prevention of Thrombosis, $9^{\text {th }}$ ed: American College of Chest Physicians Evidence-Based Clinical Practice Guidelines. Chest 2012;141:e691S-736S.

13. Kwon HL, Belanger K, Bracken MB. Effect of pregnancy and stage of pregnancy on asthma severity: A systematic review. Am J Obstet Gynecol 2004;190:1201-10.
14. Murphy VE, Gibson P, Talbot PI, Clifton VL. Severe asthma exacerbations during pregnancy. Obstet Gynecol 2005;106:1046-54.

15. Wack EE, Ampel NM, Galgiani JN, Bronnimann DA. Coccidioidomycosis during pregnancy. An analysis of ten cases among 47,120 pregnancies. Chest 1988;94:376-9.

16. Hunga CY, Hua HC, Chiua LC, Changa CH, Lia LF, Huanga CC, et al. Maternal and neonatal outcomes ofrespiratory failure during pregnancy. J Formoson Med Assoc 2018; 117:404-12.

17. Kankuri E, Kurki T, Carlson P, Hiilesmaa V. Incidence, treatment and outcome of peripartum sepsis. Acta Obstet Gynecol Scand 2003;82:730-5.

18. Vishnu Priya KM, Sheela CN, Banka S, Mahalakshmi T. Maternal and perinatal outcome of acute pancreatitis during pregnancy: A 5 year experience at a tertiary care centre. Int J Reprod Contracept Obstet Gynecol 2016;5:4041-5.

19. Murphy NJ, Quinlan JD. Trauma in pregnancy: Assessment, management, and prevention. Am Fam Physician 2014;90:717-22.

20. Chambers J, Smith N, Sehring M, Chittivelu S. Acute chest syndrome progressing to ARDS in a patient of 25 -week gestation. Case Rep Crit Care 2018;2018:3.

21. Pfeilsticker FJ, Serpa Neto A. 'Lung-protective' ventilation in acute respiratory distress syndrome: Still a challenge? J Thorac Dis 2017;9:2238-41.

22. Vianna FS, Pfeilsticker FJ, Serpa Neto A. Driving pressure in obese patients with acute respiratory distress syndrome: One size fits all? J Thorac Dis 2018;10:S3957-S3960.

23. Writing Group for the Alveolar Recruitment for Acute Respiratory Distress Syndrome Trial (ART) Investigators, Cavalcanti AB, Suzumura EA, Laranjeira LN, Paisani DM, Damiani LP, et al. Effect of Lung Recruitment and Titrated Positive End-Expiratory Pressure (PEEP) vs. low PEEP on Mortality in Patients With Acute Respiratory Distress Syndrome: A Randomized Clinical Trial. JAMA 2017;318:1335-45.

24. Catanzarite V, Willms D, Wong D, Landers C, Cousins L, Schrimmer D. Acute respiratory distress syndrome in pregnancy and the puerperium: Causes, courses, and outcomes. Obstet Gynecol 2001;97:760-4.

25. Lapinsky SE, Kruczynski K, Slutsky AS. Critical care in the pregnant patient. Am J Respir Crit Care Med 1995;152:427-55.

26. National Heart, Lung, and Blood Institute Acute Respiratory Distress Syndrome (ARDS) Clinical Trials Network, Wiedemann HP, Wheeler AP, Bernard GR, Thompson BT, Hayden D, et al. Comparison of two fluid-management strategies in acute lung injury. N Engl J Med 2006;354:2564-75.

27. Bourenne J, Hraiech S, Roch A, Gainnier M, Papazian L, Forel JM. Sedation and neuromuscular blocking agents in acute respiratory distress syndrome. Ann Transl Med 2017;5:291.

28. The National Heart, Lung, and Blood Institute PETAL Clinical Trials Network. Early neuromuscular blockade in acute respiratory distress syndrome. NEJM 2019;380:1997-2008.

29. Tobin A, Kelly W. Prone ventilation-it's time. Anaesth Intensive Care 1999;27:194-201

30. Guerin C, Reignier J, Richard JC, Beuret P, Gacouin A, Boulain T, et al. Prone position in severe acute respiratory syndrome. N Engl J Med 2013;368:2159-68.

31. Kenn S, Weber-Carstens S, Weizsaecker K, Bercker S. Prone positioning for ARDS following blunt chest trauma in late pregnancy. Int J Obstet Anesth 2009; 18:268-71.

32. Samanta S, Samanta S, Wig J, Baronia AK. How safe is the prone position in acute respiratory distress syndrome at late pregnancy? Am J Emerg Med 2014;32:687.e1-3.

33. Karam O, Gebistorf F, Wetterslev J, Afshari A. The effect of inhaled nitric oxide in acute respiratory distress syndrome in children and adults: A Cochrane Systematic Review with trial sequential analysis. Anaesthesia 2017;72:106-17.

34. Robinson JN, Banerjee R, Landzberg MJ, Thiet MP. Inhaled nitric oxide therapy in pregnancy complicated by pulmonary hypertension. Am J Obstet Gynecol 1999; 180:1045-6.

35. Netteburg D, Bsat F, Healy A, Markenson G, Plevyak M, Circeo L. The use of high-frequency oscillatory ventilation in a patient with H1N1 pneumonia. J Matern Fetal Neonatal Med 2011;24:264-6. 
Shaikh, et al:: ARDS in pregnancy and peripartum

36. Sharma NS, Wille KM, Bellot SC, Diaz-Guzman E. Modern use of extracorporeal life support in pregnancy and postpartum. ASAIO J 2015;61:110-4.

37. Nair P, Davies AR, Beca J, Bellomo R, Ellwood D, Forrest P, et al. Extracorporeal membrane oxygenation for severe ARDS in pregnant and postpartum women during the $2009 \mathrm{H} 1 \mathrm{~N} 1$ pandemic. Intensive Care Med 2011;37:648-54.

38. Moore SA, Dietl CA, Coleman DM. Extracorporeal life support during pregnancy. J Thorac Cardiovasc Surg 2016;151:1154-60.

39. Bonham CA, Patterson KC, Strek ME. Asthma Outcomes and Management During Pregnancy. Chest 2018;153:515-27.

40. Fernandes AB, Zin WA, Rocco PR. Corticosteroids in acute respiratory distress syndrome. Braz J Med Biol Res 2005;38:147-59.
41. Annane D, Pastores SM, Rochwerg B, Arlt W, Balk RA, Beishuizen A, et al. Guidelines for the diagnosis and management of critical illness-related corticosteroid insufficiency (CIRCI) in critically ill patients (Part I): Society of Critical Care Medicine (SCCM) and European Society of Intensive Care Medicine (ESICM) 2017. Intensive Care Med 2017;43:1751-63.

42. Bellani G, Laffey JG, Pham T, Fan E, Brochard L, Esteban A, et al. Epidemiology, patterns of care, and mortality for patients with acute respiratory distress syndrome in intensive care units in 50 countries. JAMA 2016;315:788-800.

43. Rush B, Martinka P, Kilb B, McDermid RC, Boyd JH, Celi LA. Acute respiratory distress syndrome in pregnant women. Obstet Gynecol 2017;129:530-5 